Los años de formación de Juan Carlos Tedesco. Su trayectoria política y académica durante las décadas del 50 y 60

Sebastián Gómez

páginas / año 12 - n 30 Septiembre-Diciembre / ISSN 1851-992X/ 2020

http://revistapaginas.unr.edu.ar/index.php/RevPaginas

DOI: http://dx.doi.org/10.35305/rp.v12i30.443

\title{
Los años de formación de Juan Carlos Tedesco. Su trayectoria política y académica durante las décadas del 50 y 60
}

\author{
The years of formation of Juan Carlos Tedesco. His political and \\ academic trajectory during the 50 s and $60 \mathrm{~s}$
}

\author{
Sebastián Gómez \\ Universidad de Buenos Aires; \\ Consejo Nacional de Investigaciones Científicas y Técnicas (Argentina) \\ sebastianjorgegomez@gmail.com
}

\begin{abstract}
Resumen
El artículo aborda la trayectoria política y académica en las décadas de los años 50 y 60 de Juan Carlos Tedesco (1944-2017). En aquella época, el maestro normal participará activamente de las tendencias izquierdistas del Partido Socialista y luego de la incipiente agrupación troskista Política obrera. También en la década del 60 comenzaron sus estudios en la carrera de Ciencias de la Educación de la Facultad de Filosofía y Letras, Universidad de Buenos Aires. Atraído por un ambiente intelectual abocado al estudio empírico y comprometido con las luchas sociales, Tedesco asumirá al registro científico como decisivo en la indagación e intervención sobre los problemas educativos. Ante el golpe de Estado de 1966 y la intervención de la UBA, el maestro normal se apresurará a finalizar sus estudios universitarios y comenzará a profesionalizar sus prácticas de investigación desde su ingreso al Instituto Latinoamericano de Relaciones Internacionales.

Al reconstruir los años de formación del cientista de la educación, el artículo arroja luz sobre algunas de las influencias que estructuraron su ya clásico libro Educación y sociedad, 18801900 (1970). En tal reconstrucción, se atiende a la condición juvenil del autor, y se sugiere que su formación permaneció modulada por un proceso híbrido entre dinámicas de modernización cultural y compromiso político.
\end{abstract}

Palabras clave

Juan Carlos Tedesco; Juventud; Formación; Política; Universidad.

\begin{abstract}
The article is about Juan Carlos Tedesco's (1944-2017) political and academic trajectory in the 50s and 60s. In those years, the normal teacher actively participated in the leftist tendencies of theSocialist Party and after in the incipient Troskist political group. Also in the 60s, he began his studies in the career of Education Sciences at the Faculty of Philosophy and Letters, University of Buenos Aires. Attracted by an intellectual environment dedicated to empirical study and committed to social struggles, Tedesco assumed the scientific record as decisive for investigation and intervention on educational problems. Before the dictatorship in 1966 and the intervention of UBA, Tedesco hastened to finish his university
\end{abstract}

Esta obra está sujeta a la Licencia Reconocimiento-NoComercial-CompartirIgual 4.0 Internacional de Creative Commons. http://creativecommons.org/licenses/by-nc-sa/4.0/ 


\section{Sebastián Gómez}

studies and begone to professionalize his research practices when he joined the Latin American Institute of International Relations.

By reconstructing the education scientist's years of training, the article sheds light on some of the influences that structured his classic book Education and Society, 1880-1900 (1970). In this reconstruction, attention is paid to the author's youth status and it is suggested that his training remained modulated by a hybrid process between dynamics of cultural modernization and political compromiso.

\section{Keywords}

Juan Carlos Tedesco; youth; training; politc; university.

\section{Introducción}

En el análisis de un derrotero intelectual es preciso desprenderse de la noción tradicional de autor/a. En otras palabras, se trata de evitar las historias biográficas hechas con acumulaciones lineales que se construyen bajo el prisma de aquello que Bourdieu (1997) denominó formas de la "ilusión retrospectiva": una suerte de abordaje en clave teleológico capaz de atribuirle a los agentes individuales intenciones y premeditaciones que conducen inexorablemente al acontecimiento histórico ya conocido. La noción de trayectoria del sociólogo francés fuga de esta ilusión al reclamar la reconstrucción de la trama y los estados de los campos que el intelectual atravesó. En definitiva, altera una historia individualizada a través de "grandes hombres" y, parafraseando a Norbert Elias (1991) en su trabajo sobre Mozart, invita a colocar la "genialidad" en configuraciones específicas.

Desde la historia intelectual, el artículo aborda el itinerario de Juan Carlos Tedesco (1944-2017) en sus años de formación, esto es, en los años 50 y 60, cuando realiza sus primeras incursiones políticas y académicas. Para tal fin, el manuscrito analiza el estado fuerzas de los campos políticos y académicos y, concretamente, las huellas, marcas y opciones que estos campos ofrecieron al joven Tedesco. De este modo, se privilegian dos planos de análisis entrecruzados: el político y el académico. A modo de hipótesis, el manuscrito sugiere que la trayectoria partidaria y académica del joven Tedesco en los años 50/60, permaneció modulada por un proceso híbrido entre dinámicas de modernización cultural y compromiso político. En otras palabras, su temprano itinerario universitario y político estuvo permeado por la expansión de la matrícula secundaria y universitaria, la movilidad social, la conformación de novedosos espacios, circuitos y estilos de socialización, la renovación de las ciencias sociales que se entremezclaron con su voluntad por la transformación política de la sociedad.

La relevancia de la indagación de los años formativos de Tedesco se fundamenta no sólo en el protagonismo del autor en los debates político-educativos locales e internacionales. También debido a que su derrotero intelectual en esos años no ha sido abordado. Los agudos perfiles político-intelectuales trazados sobre el autor 


\section{Los años de formación de Juan Carlos Tedesco. Su trayectoria política y académica durante las décadas del 50 y 60}

(Ruiz, 2015; Amar, 2017; Pulfer, 2017; Dussel, 2018; entre otros) suelen jerarquizar aquellos años en que la prolífera y versátil obra del cientista de la educación tuvo lugar, es decir, a partir de la aparición de su primer libro Educación y sociedad en la Argentina, 1880-1900(1970). En diálogo con estas contribuciones, se busca indagar en los años formativos en términos políticos y académicos de quien fuera el primer egresado en Ciencias de la Educación en comandar el Ministerio de Educación de la Nación (2007 - 2009). En este ejercicio, se reponen algunas de las múltiples marcas que aquellos años de formación dejaron en su ya clásico Educación y sociedad....

El manuscrito expone resultados producidos a través de un enfoque cualitativo, esto es, un enfoque que buscó reconstruir la trama y sentidos de la trayectoria de Tedesco entre los años 50 y 60. De ahí que se desplegaron estrategias y técnicas metodológicas de corte cualitativo. Concretamente, se recolectaron datos mediante la indagación documental (fundamentalmente, de revistas políticas y culturales) y entrevistas semi-estructuradas al propio Tedesco (abril 2015), a su hermano Luis Osvaldo (septiembre 2017) y a su compañera, Nilda León (junio 2018). ${ }^{1}$

\section{La estación política: entre el Partido Socialista y Política Obrera}

Como otros jóvenes, hacia mediados de los años 50, Luis Osvaldo Tedesco (1941) decidió sumarse a las filas del Partido Socialista (PS) a través de su centro ubicado en el barrio de Liniers. Tiempo después, influirá en su hermano menor, Juan Carlos, que lo acompañará en esta elección. Ambos participarán en las Juventudes Socialistas, que luego del derrocamiento del peronismo contaban con una notable expansión. Ingresarán a las filas juveniles a los 14 años; la edad mínima permitida para la incorporación. Aunque el principal Partido de izquierda local por entonces era el Comunista, en aquellos años la órbita soviética atravesaba una severa crisis. Puntualmente, 1956 resultó un año crítico: en febrero, el XX Congreso del Partido Comunista de la Unión Soviética arrojó luz sobre las atrocidades del stalinismo y, en el transcurso de ese mismo año, el régimen reprimió las revueltas populares en Polonia y Hungría. Presumiblemente, en esta particular atmósfera, el PS aparecía como una opción más atractiva para las inquietudes izquierdistas de los jóvenes Tedesco.

En la década del 50, en sintonía con los procesos acaecidos en los Partidos de izquierda de Europa occidental, tanto los socialistas como comunistas, experimentaron un cambio morfológico: nuevos y jóvenes intelectuales universitarios ingresaron a sus formaciones. Tal ingreso desatará una serie de tensiones con las direcciones a cargo de la orientación política y cultural. En el caso del socialismo vernáculo, la dirección político-cultural se encarnaba en Américo Ghioldi. A diferencia de la generación precedente, forjada en la lucha contra el fascismo, las/os recién llegadas/os estaban particularmente permeados/as por la

\footnotetext{
${ }^{1}$ La misma fue realizada con Hernán Amar en el marco de las actividades del Grupo interuniversitario de estudio sobre la obra de Juan Carlos Tedesco, que tiene sede en la Universidad Nacional Pedagógica (UNIPE).
} 


\section{Sebastián Gómez}

vida universitaria como por los nuevos debates y corrientes que animaban al marxismo. Paulatinamente, junto al tradicional modelo de intelectual del partido que servía como blasón de legitimidad de iniciativas partidarias, comenzó a emerger una nueva especie: el intelectual en elpartido, dispuesto a reclamar un rol específico en la elaboración de la estrategia de la organización (Petra, 2017). Si bien Luis y Juan Carlos Tedesco no tuvieron un rol protagónico en los debates de la línea estratégica socialista, siguieron con particular atención los esfuerzos de estos jóvenes por ocupar un espacio decisivo en el Partido e inclinarlo hacia la izquierda.

Aunque sin un caudal electoral relevante, el PS no sólo había participado de la alianza conservadora que puso fin al gobierno de Perón. También varios de sus cuadros integraban el gobierno de facto comandado por el General Eduardo Lonardi y, luego, el General Pedro Aramburu, dispuesto a "desperonizar la vida social" (Neiburg, 1998). Rápidamente, el régimen transitó un dilema que signarán los años por venir de la vida nacional, tanto del frondizismo (1958-1962), del breve interregno de José María Guido (1962-1963), de la débil administración de Arturo Illia (63-66), como de la autodenominada Revolución Argentina (1966-1973): el rumbo de la economía y la asimilación política de las masas peronistas (Altamirano, $2001)^{2}$. El marcado cariz antipopular del régimen alejó rápidamente a franjas intelectuales que lo habían comprendido como una solución a los "excesos" del peronismo. Comenzarán así un proceso de viraje hacia posiciones antiliberales. A su vez, la persistente adhesión peronista de las masas será una preocupación medular entre franjas del comunismo y del socialismo, compelidos a reponer los vínculos tejidos con el mundo operario que el proscrito movimiento les había arrebatado (Herrera, 2016).

A diferencia del Partido Comunista (PC), el socialismo contaba con una estructura más abierta y un carácter menos doctrinario. Como en otros países, el socialismo local experimentará, hacia fines de los años 50 , abiertas disputas entre tendencias liberales, renovadoras o izquierdistas. Tedesco, que ingresó al PS hacia 1958, se formará en estas acaloradas polémicas. Entre 1955 y 1961, resulta posible establecer dos ciclos de fraccionamientos en el interior del socialismo (Tortti, 2009). En el primero, desde septiembre de 1955 hasta julio de 1958, la preeminencia de Ghioldi será paulatinamente impugnada por la corriente renovadora. De neto perfil antiperonista, el ghioldismo contaba con un fuerte compromiso con la Revolución Libertadora y la Unión Cívica Radical del Pueblo (UCRP). La fracción renovadora, que agrupaba a moderados y jóvenes de izquierda, invertía la ecuación trazada por el ghioldismo: no se trataba de defender la Revolución Libertadora sino la soberanía de la clase obrera; como en otras expresiones de izquierda por entonces, esta fracción estaba en tránsito desde un antiperonismo visceral al rechazo del antiperonismo gubernamental (Sigal, 1991).

El triunfo de Arturo Frondizi en las elecciones de febrero de 1958 parecía modificar la escena política nacional. Alcanzado el gobierno en acuerdo con el peronismo, la

\footnotetext{
${ }^{2}$ Aporía también tematizada por los tempranos trabajos de Portantiero (1973) y O’Donnell (1977).
} 


\section{Los años de formación de Juan Carlos Tedesco. Su trayectoria política y académica durante las décadas del 50 y 60}

nueva administración había despertado expectativas entre franjas intelectuales de izquierda. Sin embargo, a los pocos meses de asumir, sus medidas antipopulares colocaron en crisis las esperanzas del arco progresista (Terán, 1991). Entre otras medidas, la administración reformó el artículo $28^{\circ}$ de la Ley de Educación en septiembre de 1958 que habilitó a las universidades católicas a expedir títulos universitarios. La medida desató vertiginosas disputas callejeras entre quienes defendían el carácter laico de la universidad y aquellos que pretendían liberar la expedición de títulos del monopolio estatal. Tal vez, la acalorada contienda, recordada como "la laica contra la libre", donde el PS defendió tenazmente la laicidad, haya despertado ciertas perplejidades en la sensibilidad política del joven Tedesco, formado en una escuela primaria católica.

En el marco de la "traición frondizista", la tendencia renovadora redobló sus esfuerzos de acercamiento a la clase obrera y sus dirigentes peronistas. El ghioldismo persistió en su cariz liberal y antiperonista. Las opciones divergentes estallarán en el $44^{\circ}$ Congreso del PS: los renovadores que detentaban la mayoría, decidieron separar del Partido a veteranos dirigentes como Nicolás Repetto, Jacinto Oddone y al propio Américo Ghioldi, quienes luego darán vida al Partido Socialista Democrático (PSD). Los renovadores animarán un nuevo nucleamiento: el Partido Socialista Argentino (PSA). Comenzaba un segundo ciclo de disputas en el socialismo, pero ahora en el interior del PSA, donde convivían dos tendencias: moderados e izquierdistas (Tortti, 2009). A diferencia del ghioldismo, ambas compartían una apertura al peronismo, pero el grado de acercamiento que la juventud proponía, en términos políticos y gremiales, era excesivo para el ala moderada. La izquierda socialista, con la que se alineó Tedesco, imaginaba una inevitable radicalización de la clase obrera peronista y una salida del tipo insurreccional. Para los moderados, el horizonte socialista era inescindible de la vía democrática. Además de La Vanguardia, que era conducida por Alicia Moreau desde 1956, la fracción moderada contaba con el periódico mensual Sagitario, que reapareció entre junio de 1958 y 1961 bajo la dirección de Carlos Sánchez Viamonte. Junto con la huelga en el frigorífico Lisandro de la Torre, durante enero de 1959, de la que participarán activamente jóvenes del PSA y terminará por colocar en crisis el pacto entre el frondizismo y el peronismo, otro hecho ocurrido a principios de aquel mes marcará un ascenso de las filas juveniles: la Revolución Cubana. Los socialistas argentinos apoyaban la gesta cubana desde mucho antes de su triunfo, tanto por su cariz antidictatorial y democrático como por su proyección antiimperialista. A diferencia de la reticencia comunista o la indiferencia de sectores peronistas, en enero del 59 el PSA adhirió abiertamente a las proclamas del Movimiento 26 de Julio. De hecho, se convirtió en el más "cubanista" de los Partidos. Tal identidad, junto con el apoyo a las crecientes luchas obreras, producirá una segunda afluencia juvenil a sus filas (Tortti, 2009). Esta atmósfera influirá en la sensibilidad política de Tedesco, deslumbrado por la primera experiencia socialista en idioma castellano, que además era comandada por unos jóvenes irreverentes. 


\section{Sebastián Gómez}

En el marco de esta efervescencia, la corriente de izquierda del PSA no sólo se hará cargo de la dirección de La Vanguardia a través de David Tieffenberg. Además, construirá órganos de expresión propios: entre marzo de 1960 y septiembre de 1961 editarán la revista mensual Situación (nueve números) que declaraba, en su editorial de apertura, una afiliación al marxismo "nutrida de la savia nativa". Clausurada para los liberales, la publicación asumía explícitamente una perspectiva marxista, latinoamericana y al servicio de la clase obrera. También mostraba un perfil claramente antistalinista y solía replicar escritos que aludían a construcciones políticas díscolas respecto a la órbita soviética: la experiencia china, yugoslava o cubana. A su vez, entre octubre de 1960 y noviembre 1961, jóvenes del Partido editaron la revista Che (27 números), que combinó un discurso político claramente de izquierda con una propuesta cultural y periodística moderna (Tortti, 2014).

En el año 61, las tensiones políticas en el interior del PSA estallarán: los renovadores pretenderán expulsar al ala izquierdista, que cada vez era más influyente. La fracción juvenil enfrentó la maniobra amparándose en el hecho de ser la "mayoría legítima”, al tiempo que reorganizó la Mesa Ejecutiva del Comité Nacional con Tieffenberg como Secretario General y rebautizó la publicación partidaria con el título La Vanguardia "roja”. En los hechos, comenzaron a funcionar dos Partidos en uno: al poco tiempo, el ala moderada pasará a denominarse PSA Casa del Pueblo y el ala izquierdista PSA de Vanguardia (PSAV) (Tortti, 2009). Las juventudes socialistas, donde por entonces militaba Tedesco, fue el sector que más compactamente se alineó en la nueva Secretaría Tieffenberg.

Despojado de los viejos moderados, las/os jóvenes izquierdistas prosiguieron en la construcción de una identidad propia. El $46^{\circ}$ Congreso realizado en Córdoba entre el 29 de septiembre y el $1^{\circ}$ de octubre de 1961, resultó fundacional. Con un indisimulado orgullo, se autoproclamaron como "la izquierda más joven del país", en momentos en que la cuestión generacional era largamente evocada en la trama político-cultural. Además de redoblar la identificación con el proceso cubano, el Congreso asumió un linaje disruptivo para la tradición socialista: el marxismoleninismo. Tal osadía supuso una operación doble: la desafiliación de la Internacional Socialista y la reorganización de la trama organizativa interna. Reorganización que se verá acelerada por el nuevo golpe militar del 29 de marzo de 1962 que desalojó al frondizismo del gobierno, luego del triunfo del peronismo en las elecciones de marzo de 1962. Aquella estructura demo-liberal y abierta que permitía a la militancia circular por centros, federaciones o "tertulias de amigos", como aseguraba Giussani en La Vanguardia roja (1962, p. 5), debía ceder a una compulsiva centralización. La homogeneización de la organización, el crecimiento de las actividades clandestinas, las polémicas sobre el vínculo con el peronismo, llevaron a la deserción de varios militantes durante 1962 que no comprendían o compartían el rumbo del Partido (Tortti, 2009). Uno de ellos fue Tedesco, que ya en la universidad asumió con perplejidad el ofrecimiento de formar parte del Consejo Central de las Juventudes Socialistas. 


\title{
Los años de formación de Juan Carlos Tedesco. Su trayectoria política y académica durante las décadas del 50 y 60
}

La primera estación política de Tedesco significó la apertura a una trama de debates y una literatura de corte marxista desconocida en su inmediata atmósfera cultural. Nacido en la localidad porteña de Devoto, al poco tiempo su familia adquirió un terreno en la calle Larrea 2289 del barrio Lomas del Mirador, perteneciente al popular partido de La Matanza, donde Tedesco pasará buena parte de su infancia y años juveniles. Hijo de inmigrantes, su padre llevaba adelante un almacén en el barrio. Luis, como Juan Carlos, colaboraban sistemáticamente. También hacía lo propio su madre, Elena Atallah, que además asumía las tareas domésticas. Con la ayuda de los tíos Onofrio y Nicolás, enrolados en el gremio de la construcción, la familia Tedesco levantó una casa que siempre parecía inconclusa. El propio hermano de Juan Carlos ha recreado de modo poético los contornos de aquel barrio popular $y$, particularmente, del hogar que en su persistente indeterminación, sembraba angustias:

\begin{abstract}
"El dilema constructivo de Lomas del Mirador viene de antaño, acaso de la sucesión acumulada de planos caseros que proyectaban el final de obra de nuestras casas nunca terminadas. Los recursos escasos, la ausencia de un arquitecto que mantuviera incólume la idea original, ese no sé qué que quedaba sin realizar, como un balbuceo del espacio prometido a la ilusión afectiva, todo ello crispado por el temporal alucinado de grietas prematuras asolando los cimientos del origen, y todo ello a su vez inmerso en el discurso amenazante de la ejecución presupuestaria, produjeron, sin ser nosotros partícipes conscientes de su gestación y posterior ideario, el fantasma. Toda casa en construcción -y en Lomas del Mirador todas las casas son en construccióntiene su fantasma" (Tedesco, 2006, p. 80).
\end{abstract}

Prácticamente, el barrio no contaba con vías de acceso a la cultura letrada, ni en el hogar circulaban libros. Pero es preciso rehuir de una concepción del espacio barrial en términos ahistóricos o con delimitaciones rígidas; más bien, resulta un locus poroso a trayectorias heterogéneas y dinámicas históricas (Van Gelder, et.al., 2013). En ese sentido, la escasa presencia de librerías no debe soslayar otros procesos tales como el crecimiento en las tasas de la matrícula educativa de nuevos segmentos sociales durante los años 50, que co-constituyeron a la propia identidad barrial e inaugurarán otras posibilidades. Era el caso de los hermanos Tedesco, que comenzaron sus estudios en el católico colegio San Rafael de los Hermanos del Sagrado Corazón en el barrio porteño de Devoto. Luego, Luis optará por el Colegio Nacional, situado en Liniers, mientras Juan Carlos proseguirá en el Colegio Normal ubicado en el barrio de San Justo, lindero a Lomas de Mirador ${ }^{3}$.

Como otras capas trabajadoras, en los años 50 la familia Tedesco obtuvo recursos necesarios para solventar el acceso de sus hijos a nuevos niveles educativos, participando así de la creencia colectiva que asociaba las credenciales educativas con el ingreso a las lábiles clases medias (Adamovsky, 2009). Tal oportunidad, seguramente haya sido vivida por los jóvenes Tedesco con particular

\footnotetext{
${ }^{3}$ Allí conocerá a una figura significativa en su recorrido intelectual: el pedagogo Juan P. Nervi.
} 


\section{Sebastián Gómez}

responsabilidad: en definitiva, encarnaban viejas aspiraciones. El acceso a los estudios secundarios, inaccesible para sus padres, fomentó el vínculo con una cultura ilustrada que el PS extenderá considerablemente. Si en Bourdieu (2011) la transmisión doméstica y la apropiación del capital cultural objetivo en el seno familiar resulta decisivo al estructurar duraderas disposiciones y un sentido de los límites, las dinámicas de modernización cultural suministradas por el ingreso a circuitos educativos inauditos como la experiencia política en el PS, contribuyeron a la crisis de los parámetros culturales provenientes de un barrio y una familia obrera. La copiosa bibliografía marxista que circulaba por el arco socialista, junto con la prolífera red de revistas (Situación, Che, etc.), periódicos (Sagitario, Vanguardia, Vanguardia "roja"), espacios de formación y los acalorados debates del Partido, despertaron en Tedesco una serie de intereses políticos y teóricos novedosos. Cautivado por lecturas heterodoxas, vanguardistas y alejadas de los cánones stalinistas del linaje marxista, el maestro normal siguió con atención los intentos de jóvenes socialistas por resolver un típico clivaje de aquellos años entre nación y teoría marxista; entre el convulsionado Tercer Mundo y la literatura revolucionaria (Georgieff, 2008). Clivaje que también Tedesco intentará dirimir tiempos más tarde desde una epistemología marxista en el terreno educativo. Esta primigenia experiencia en las filas socialistas, que articuló el compromiso político intenso con un prolífero debate teórico marxista, amplió decididamente los horizontes culturales del joven militante; intelectualidad y política pasarán a constituir un vínculo tan productivo como inescindible que será vivido en clave vanguardista y con una intensidad inusitada.

Aun en su búsqueda del peronista mundo obrero, la influencia principal de la juventud socialista siguió siendo el ámbito universitario, particularmente, la Facultad de Filosofía y Letras (FFyL) de la Universidad de Buenos Aires (UBA). Varios jóvenes socialistas acompañarán al otrora presidente del PS, José Luis Romero, y al círculo de intelectuales "frondizistas" que lo secundaban, entre ellos Ismael Viñas y Noé Jitrik, en la creación de nuevas carreras e institutos. Las iniciativas de Gino Germani en el ámbito sociológico compartían con la Juventud Socialista una persistente preocupación: comprender el fenómeno peronista desde un nuevo prisma (Amaral, 2018). Algunas/os de estos jóvenes socialistas serán Miguel Murmis, Hugo Calello, Ruth Sautu, Juan Carlos Marín, Torcuato Di Tella o Jorge Graciarena. Los trabajos de estos dos últimos militantes animarán la reflexión socio-histórica de Tedesco en su libro Educación y Sociedad...4 En el marco de un ascenso sostenido de la matrícula de la UBA, que entre 1958 y 1966 creció en un 35.7 por ciento (Califa, 2014), tal vez la marcada presencia de jóvenes socialistas en la FFyL haya influido en la sensibilidad académica de los hermanos Tedesco. Ambos

\footnotetext{
${ }^{4}$ Aunque sin la centralidad de estos jóvenes, también en el libro se verán referencias a figuras emblemáticas de la tradición socialista como Alejandro Korn, Jacinto Oddone y Américo Ghioldi. Este último se desempeñaba como docente en la carrera de Pedagogía y luego de Ciencias de la Educación de la UBA
} 


\section{Los años de formación de Juan Carlos Tedesco. Su trayectoria política y académica durante las décadas del 50 y 60}

decidieron continuar sus estudios en esta Facultad: Luis, en Letras; Juan Carlos, en Ciencias de la Educación.

Será precisamente en esta casa de estudio, tan animada por el activismo y la participación en las luchas sociales, donde se teja la segunda incursión militante de Tedesco: Política obrera, organización al que ingresará a mediados de los años 60. Si, según Gramsci (2003 [1949], p. 30), una revista puede asumir las funciones de un partido político, la aparición de Política obrera lo certifica: fundada en marzo 1964, la revista estructuró, al mismo tiempo, al pequeño colectivo político homónimo de perfil troskista. En el primer número, se señalaba con claridad una escisión sobre la cual la revista fundaba su propósito: "la tremenda desvinculación entre el marxismo y el proletariado" (p. 2). De allí su objetivo doble: primero, difundir las posiciones del marxismo revolucionario, combatiendo particularmente la ideología peronista y al stalinismo; segundo, orientar los conflictos operarios. Política obrera utilizaba su inserción universitaria para reclutar cuadros políticos, destinados a animar las luchas obreras. Para tal fin, se valió primero de la revista mencionada que contó con cuatro números entre marzo de 1964 y marzo de 1965. La publicación frecuentó la polémica con otras tendencias de izquierda. Así siguió de cerca la crisis del Partido en el que había militado Tedesco: PSAV5. Hacia 1964, la organización comenzó a editar, además, unos suplementos que señalaban su postura ante diversos temas, tales como el Retorno de Perón (noviembre de 1964); en junio de 1965, empezó la edición de Suplementos periódicos que también abordaban temas de la realidad nacional e internacional; en rigor, tales suplementos estaban pensados como parte de las tareas para la creación de un "periódico revolucionario" que aparecerá hacia mediados de 1966 en forma de revista-boletín y circulará en forma clandestina. Si se compara con la revista inicial, es posible concluir que paulatinamente las publicaciones de la organización adquirieron un tono cada vez más cercano a las luchas fabriles.

A pesar de sus limitaciones para incorporar operarios, Política Obrera desde su nacimiento desplegó una actividad sistemática hacia la clase trabajadora: reparto de folletos en las puertas de las fábricas; intervención en conflictos; apertura de sus órganos de prensa a listas sindicales (Kohn, 1999). Tedesco participó activa y comprometidamente de este ejercicio militante, pero entrará en crisis cuando, ya producido el golpe de Onganía en 1966, el Partido asuma las "Tesis sobre proletarización" en abril de 1967, que buscaban resolver el hiato entre intelectualidad revolucionaria y clase obrera (Coggiola, 2006). De manera compulsiva, la organización promovió y controló que todos sus miembros universitarios debían ingresar a trabajar en fábricas. Como otras fuerzas de izquierda de la época, Política Obrera transcurría por una paradoja: descalificaba con el epíteto "pequeño burgués" a la intelectualidad pero, al mismo tiempo, le reconocía capacidades políticas superiores respecto a la clase operaria a la cual

\footnotetext{
${ }^{5}$ A propósito, el número doble 2-3 (septiembre de 1964) abrió con un artículo de Roberto Gramar (p. 9-16).
} 


\section{Sebastián Gómez}

debía dirigir. Las directivas fueron resistidas y largamente discutidas por distintos militantes, que finalmente optaron por alejarse de la organización. Uno de ellos fue Tedesco, que desistió hacia 1968: de manera similar a su experiencia socialista, la nueva incursión política finalizaba a causa de cambios organizativos.

Si se asume por un momento la definición descriptiva del intelectual suministrada por Bourricaud (1980), esto es, agentes que se apoyan en la posesión de un saber para legitimar pretensiones de intervención en la esfera social, el imperativo de la proletarización colocaba en crisis tal pretensión. El perfil intelectual ofrecía a Tedesco un conjunto de reconocimientos, "honores" y gratificaciones, es decir, un status en términos weberianos (1944 [1922]). La renuncia a tal status, suponía la dimisión al acceso a bienes restringidos y a una estima social que acarrea (real o imaginariamente) el estilo de vida del colectivo intelectual. Una decisión altamente costosa para una persona dispuesta a defender el capital cultural trabajosamente alcanzado que le había permitido tomar distancia del ambiente obrero original.

En línea con su experiencia socialista, Política Obrera supuso para Tedesco una reedición de su opción antistalinista, de la firme voluntad por participar en las luchas obreras y una formación teórica que cultivaba un marxismo en una clave heterodoxa, vanguardista y sin confianza en las bondades de una burguesía industrial; en el proletariado, se anidaba la esperanza de un nuevo orden. Pero también le otorgó una perspectiva especialmente crítica del peronismo, de las opciones políticas armadas y lo acercó estrechamente al ideario troskista.

Como corolario de la formación y debates en Política obrera, Tedesco se sintió atraído por el pensamiento troskista de Milcíades Peña y su revista Fichas (19641966), que resultó un insumo relevante en Educación y Sociedad, 1890-1900. El filón historiográfico del joven Peña estaba animado por una serie de coordenadas: i) la ausencia en la clase dominante oligárquica de alguna estrategia de desarrollo nacional a largo plazo o de un proyecto regido por una lógica de innovación tecnológica o reinversión productiva; ii) distancia de la perspectiva historiográfica que reducía la oligarquía al imperialismo, mostrando así los márgenes y opciones que ésta tuvo para sortear la subordinación del país; iii) la oligarquía, a diferencia de tesis revisionistas o de la izquierda nacional, no sólo era capitalista sino que además guardaba una unidad de intereses con la burguesía industrial. En otras palabras, la configuración de la clase dominante resultaba relativamente homogénea, por lo que sus disputas se estructuraban alrededor de la distribución del excedente, sin llegar jamás a cuestionar al propio sistema; iv) la relativa dominación por parte de la clase dominante en la historia vernácula (aun en el caso de los movimientos populares como el radicalismo o peronismo, que aparecen como estructuralmente impotentes para cambiar las bases del dominio); v) De todos modos, esta unidad de intereses entre burguesía terrateniente e industrial no implicaba una lisa identidad, por lo que el Estado permanecía animado y sensible a sus disputas (Tarcus, 1996).

Aunque excede al artículo detectar la influencia troskista de Peña sobre el filón historiográfico de Tedesco, es posible advertir aquellas claves historiográficas en 


\section{Los años de formación de Juan Carlos Tedesco. Su trayectoria política y académica durante las décadas del 50 y 60}

Educación y sociedad... El joven maestro normal se mostraba reacio a adjudicarle un carácter progresista a la oligarquía capitalista; (i) pero, simultáneamente, era sensible a exponer las opciones, debates y proyectos educativos disimiles al interior de una clase dominante (ii) relativamente homogénea (iii) como persistente en la dirección del sistema educativo (iv) y de un Estado poroso al conflicto socioeducativo $(\mathrm{v})$.

La estación académica: la Facultad de Filosofía y Letras de la Universidad de Buenos Aires

En su libro Nuevas reflexiones sobre la revolución de nuestro tiempo (1990), Ernesto Laclau realizó una sugestiva dedicatoria: "A Viamonte 430, donde todo empezó".

Viamonte 430, ofició en los años 50 de sede de la FFyL hasta 1962, cuando se trasladó a la Avenida Independencia 3065, aunque buena parte de sus actividades siguieron funcionando en el centro porteño. Posiblemente, el mito de origen en que incurre Laclau se deba a que la FFyL resultó una protagonista estelar del proyecto modernizador de aquellos años. Más aún, la evocación de la calle, antes que la propia Facultad, seguramente responda al enclave cosmopolita e iconoclasta donde se encontraba: además de bares, cines y librerías que modulaban la sociabilidad estudiantil, funcionaba desde 1958 en la calle Florida el Instituto di Tella, decisivo en las dinámicas de modernización de la cultura académica y artística. Al igual que para Laclau, la por entonces efervescente casa de estudio a la que Tedesco ingresará en julio de 1962, incidirá profundamente en su formación. Como buena parte de las y los estudiantes, el maestro normal no formaba parte precisamente de "los herederos" (Bourdieu y Passeron, 2003 [1964]); más bien integraba las filas de la primera generación universitaria. Quizás por ello, y como el 66 por ciento del estudiantado de la Facultad, Tedesco se vio compelido a alternar sus estudios con ocupaciones remuneradas (UBA, Censo de alumnos, 1964).

La FFyL permaneció signada por dos procesos hacia mediados de los años 50: la pretendida desperonización y el proyecto modernizador. Tal proyecto hacia mediados del siglo XX se había estructurado como una cabal respuesta al fantasma comunista que, en el caso latinoamericano, comenzaba a gravitar con particular ascendencia luego de la Revolución Cubana: se trataba de establecer cuáles eran las condiciones para lograr una modernización de las sociedades que evitase la senda comunista. Este ideario, se entremezcló con el retorno a las universidades de intelectuales reformistas que habían permanecido alejadas/os de la academia durante el peronismo y ahora reingresaban, ocupando muchos de ellos roles de conducción. Propuesto por el régimen de Lonardi, pero apoyado también por organizaciones estudiantiles, el socialista José Luis Romero asumió el cargo de Rector interventor de la UBA en octubre de 1955. Entre el 57 y el 62 en la FFyL, se crearon las siguientes carreras: Ciencias de la Educación (mayo del 57, que reemplazó a la antigua Pedagogía); las pujantes Sociología y Psicología (noviembre 


\section{Sebastián Gómez}

del 57); Ciencias Antropológicas (septiembre de 1958); Historia de las Artes (a mediados del 62). En octubre de 1957, se dictó un nuevo plan de estudios para la carrera de Filosofía y al año siguiente para las carreras de Historia y Ciencias de la Educación. Como parte del espíritu renovador, la Facultad implementó la departamentalización y promovió la formación de institutos y centros de investigación. Así, en marzo de 1957, el Consejo Superior de la UBA aprobó el cambio de nombre del Instituto de Didáctica por Instituto de Ciencias de la Educación. La mudanza del nombre denotaba un clivaje entre enseñanza (que pasará a manos del Departamento de Ciencias de la Educación) e investigación (concentrada en el Instituto) (Carlino, 1993). En conjunto, las modificaciones apuntadas tendieron a dotar a los estudios de una impronta especializada y enfatizar el trabajo empírico, rompiendo así con el modelo antipositivista y ensayista de décadas anteriores (Buchbinder, 1997). Se asistía, parafraseando a Bachelard, a una suerte de ruptura epistemológica.

En la FFyL, una figura decisiva en la renovación de los estudios sociales y la fundación de una sociología pretendidamente científica será el ítalo-argentino Gino Germani. Nombrado profesor titular de la Cátedra de Sociología General en 1955, dos años más tarde ocupará el cargo de Director de la carrera de Sociología y del Instituto de Sociología de la UBA. Preocupado por sortear las derivas totalitarias fascistas o comunistas, Germani instó al estudio empírico predominantemente cuantitativo, interdisciplinario y a gran escala de la sociedad argentina. Su monumental obra Estructura Social de la Argentina (1955), que constituyó la primera pesquisa local basada en los datos aportados por los primeros cuatro censos generales de población entre 1869 y 1947, “demostraba” las dinámicas modernizadoras en el país. A partir de la ilación de una descomunal labor entre investigación, traducción, docencia y edición, Germani se constituyó en maestro de toda una camada de académicas/os (Blanco, 2006). Entre otros, del propio Tedesco, que en su libro Educación y sociedad... no sólo reparará continuamente en las investigaciones germanianas. Además, a contramano de las perspectivas predominantes en la historia de la educación, comulgará con el afán por fundamentar empíricamente sus análisis. De todos modos, si bien Germani había colocado en estos años en un lugar central la cuestión de las clases sociales, la misma había permanecido desgajada de la problemática marxista. El asunto será impugnado por distintos jóvenes, muchos de ellos cercanos al propio Germani (Sarlo, 2001; Murmis, 2010). Un gesto que también se divisará, implícitamente, en el libro del joven Tedesco, tan permeado por la epistemología marxista.

Estudios recientes sobre la UBA en los años 50 han señalado, a contrapelo de una extendida perspectiva historiográfica, ciertas continuidades entre las políticas durante el peronismo (1946-1955) y los denominados “años dorados” (1955-1966) (Riccono, 2016). Este enfoque permite arrojar luz sobre posiciones residuales en la propia FFyL. Tal vez, en el ámbito educativo una figura representativa sea la de Juan Mantovani, que se desempeñó como titular en diversas materias desde 1955, y en 1957 resultó el primer director de la carrera y del Instituto de Ciencias de la 


\section{Los años de formación de Juan Carlos Tedesco. Su trayectoria política y académica durante las décadas del 50 y 60}

Educación hasta que la muerte lo sorprendió a fines de 1961 en Alemania. Influenciado por el liberalismo espiritualista y, más concretamente, por el idealismo neokantiano, rechazaba cualquier afán científico o positivista para abordar el problema educativo (Cao \& Gagliano, 2006). En 1962, cuando Tedesco ingresó en la carrera de Ciencias de la Educación, Mantovani será sustituido en la dirección del Departamento por una docente vinculada a las iniciativas de Gino Germani: Gilda Romero Brest, quien hacia fines de 1965 también se hará cargo del vicedecanato de la Facultad. La sustitución era mucho más que una danza de nombres: expresaba un proyecto que, anclado en un optimismo desmesurado en torno a la ciencia, buscaba transformar la carrera en clave científica y profesional. En línea con los preceptos germanianos, se asumía que el mundo educativo reclamaba la intervención del especialista; los estudios de los problemas educativos concretos debían extenderse hacia una intervención tendiente a la modernización de la sociedad y del propio sistema educativo.

Germani encontrará un socio en la renovación de los estudios sociales en el decano de la Facultad entre 1962 y 1965: José Luis Romero, alejado del socialismo a principios de 1962. Compartían el optimismo modernizador. Este historiador, conocido por Tedesco en sus años socialistas, será otra de las influencias decisivas en Educación y sociedad.... En 1958 se crearon la cátedra Historia Social General y el Centro de Estudios de Historia Social General en la FFyL, ambos dirigidos por Romero que renovarán la perspectiva historiográfica al develar la trama profunda y social de la vida histórica (Acha, 2005). En torno al proyecto romerista de inaugurar una historia social desde la FFyL, se reunirá una camada de intelectuales, muchos de ellos jóvenes varones, con los que Tedesco también establecerá diálogos conceptuales en su libro: Tulio Halperin Donghi, Ezequiel Gallo, Sergio Bagú, Roberto Cortés Conde y José Carlos Chiaramonte.

Animado por la renovación de las flamantes ciencias sociales y la perspectiva historiográfica, Tedesco estructurará un novedoso linaje para dirimir la historia de la educación (Ruiz, 2015; Pulfer, 2017; Dussel, 2018). En Educación y Sociedad... se vislumbra un debate historiográfico fundamentalmente con dos actores gravitantes en el campo educativo y, particularmente, en la carrera de Ciencias de la Educación de la FFyL-UBA en los años 60: Manuel Solari y Gustavo Cirigliano. Luego del golpe de 1966, el primero había permanecido en la academia y se desempeñaba como Titular de Historia de la Educación Argentina en la FFyL. En sintonía con la visión espiritualista de Mantovani, Solari (1949) modulaba una historiografía educativa eminentemente político-institucional y a partir del papel de reconocidos pedagogos. A esta historiografía de corte liberal y espiritualista que desgajaba la historia de los procesos sociales, Tedesco opondrá un nuevo enfoque relacional entre sociedad y educación. Quizás este enfoque historiográfico diverso haya llevado a Tedesco a subestimar la memorización de ciertos hechos político-institucionales al momento de rendir la asignatura a cargo de Solari en agosto de 1967, por lo que obtuvo la módica calificación de "bueno" (Archivo, FFyL-UBA). 


\section{Sebastián Gómez}

El segundo oponente será Gustavo Cirigliano. Proveniente de ambientes católicos, el autor no sólo se había insertado en el Departamento de Ciencias de la Educación con posterioridad al golpe de Estado en 1966; también participaba, desde junio de 1969, en la cartera educativa de la administración comandada por Onganía. Uno de los Ministros de Educación de esta administración, José Astigueta, promovió una serie de iniciativas educativas hacia 1968 que constituían la segunda ofensiva de sectores católicos sobre el sistema educativo luego de la reforma de la Ley de Educación durante el frondizismo. Entre otros aspectos, los proyectos del Ministro buscaban introducir la escuela intermedia lo que, simultáneamente, abría posibilidades de extender la oferta educativa del ámbito privado. Se trataba de una escuela intermedia de cuatro años con perfil técnico, destinada a la mayoría de la población de entre 11 y 14 años que no estaba en condiciones de continuar los estudios y podía así obtener una rápida inserción al mundo laboral. (Rodríguez, 2013). Los trabajos de Cirigliano (1967; 1969) oficiaban como una defensa de esta reforma (Suasnabar, 2004). Ya alejado de la vertiente espiritualista, el pedagogo se mostraba cercano al ideario del desarrollismo y revalorizaba la perspectiva positivista. Aún sin base empírica original, en sus trabajos Cirigliano estableció una identidad entre las necesidades del modelo agroexportador y los orígenes del sistema educativo; en otras palabras, la fundación de este último había respondido a las exigencias técnicas del primero. Sin embargo, se había operado un desacople cuando la oligarquía liberal se aferró al espiritualismo, por lo que el intento del positivismo científico-experimental quedó inconcluso. El ejemplo típico de este hiato Cirigliano lo encontraba en el fracaso de la reforma Saavedra Lamas en 1916.

Si bien, a diferencia de la historiográfica asocial de Solari, los trabajos de Cirigliano establecían un dinámico vínculo entre educación y sociedad, el modo de tratarlo será fuertemente impugnado por Tedesco. El oriundo de Lomas del Mirador, propondrá una sugestiva hipótesis en su libro: la estructuración del sistema educativo, esto es, entre 1880-1900, no había respondido a las necesidades económicas del modelo económico agroexportador, tal como sugería Cirigliano, sino a los intereses políticos de los grupos dirigentes; en su origen, el sistema educativo tuvo una función política antes que económica. Según Tedesco, ante la creciente demanda de sectores medios por el acceso a mayores niveles educativos hacia fines del siglo XX, la oligarquía respondió a través de la expansión y fragmentación del sistema educativo en varias escuelas técnico-profesionales a fin de autonomizar los trayectos educativos propios de la élite directiva.

Al fundamentar tal hipótesis, Tedesco dejaba entrever su afinidad y atención a las novedades provenientes del marxismo, ya que aludió a un pasaje del libro Intelectuales y organización de la cultura (1960), donde Gramsci criticaba la reforma educativa fascista en Italia durante los años 20: la multiplicación de los tipos de escuela profesional otorgaba una impresión democratizadora pero, en rigor, eternizaba las desigualdades. Es difícil determinar las vías de acceso de Tedesco al pensamiento gramsciano, pero además de la atmósfera políticointelectual de los años 60, tan permeable al debate marxista, tal vez el maestro 


\section{Los años de formación de Juan Carlos Tedesco. Su trayectoria política y académica durante las décadas del 50 y 60}

normal se acercó al comunista italiano al cursar la materia Sociología Sistemática de la FFyL a cargo de un docente con quien establecerá asiduos diálogos: Juan Carlos Portantiero. Igualmente, otro amigo entrañable del sociólogo argentino, el autodidacta "Pancho" Aricó, se constituirá para Tedesco en un referente intelectual $\mathrm{y}$ un decisivo puente con los debates en la izquierda italiana y el pensamiento gramsciano.

Las influencias de los nuevos enfoques anidados en la FFyL sobre Tedesco no se reducían al plano de las ciencias sociales o la historiografía. Incluso el modo epistemológico de acercarse al objeto de estudio guardaba deudas con aquella casa de estudio. Producto de las posibilidades del plan de estudios, pero también de la atmósfera interdisciplinaria de aquellos tiempos, Tedesco cursó dos materias optativas a cargo de Gregorio Klimosky, pertenecientes al Departamento de Filosofía: Lógica y Filosofía de la Ciencia. El deslumbramiento fue tal que Tedesco decidió cursar dos veces estas unidades curriculares y hasta llegó a evaluar su traspaso a la carrera de Filosofía. Además de tejer perdurables lazos de amistad con docentes de aquellas asignaturas, como Telma Barreiro y Oscar Nudler, el maestro normal se llevó una enseñanza que estructuró epistemológicamente su labor hermeneútica sobre los orígenes del sistema educativo: la clave de la investigación científica residía en formular y contar con una hipótesis capaz de explicar una gran cantidad de problemas.

La hipótesis del cientista de la educación sobre el origen del sistema escolar estaba destinada a intervenir en una escena política animada por el debate sobre la reforma educativa. Como otras figuras de su época, Tedesco actuaba como un intelectual: sus preocupaciones no brotaban de una acotada agenda académica sino de un modo preciso de comprender y participar de los antagonismos sociales. La preocupación por impugnar la reforma seguramente haya sido modulada tanto por sus años de militancia política como por la activa resistencia de la comunidad educativa con la que Tedesco mantenía fluidos vínculos: egresado como maestro normal, en los años 60 se desempeñó como docente en el hogar escuela de Ezeiza y en escuelas secundarias ubicadas en La Matanza, Mataderos y Liniers; también, aún joven, ofició como docente y vicedirector de la escuela Domingo Faustino Sarmiento en el barrio de Flores, que dirigía su antiguo y entrañable docente Juan Ricardo Nervi.

Tal vez por estas persistentes y comprometidas inquietudes educativas, en 1965 Tedesco decidió integrarse a las actividades del Departamento de Extensión Universitaria (DEU) dependiente del Rectorado de la UBA. Fundado en enero de 1956, el DEU constituyó, quizás, la primera estructura institucional de extensión de esta longeva universidad. Bajo un enfoque interdisciplinario, propuso articular las actividades de extensión, docencia e investigación a la luz de problemáticas propias de los sectores populares. La iniciativa respondía en buena medida a una preocupación epocal de grupos estudiantiles: vincular la comunidad académica con los sectores populares. El programa más regular y ambicioso del DEU resultó el Centro de Acción Comunitaria establecido en la popular Isla Maciel. En homenaje a la Reforma del 18, la fecha de comienzo formal fue junio de 1956. Se inició a través 


\section{Sebastián Gómez}

de la apertura de una escuela vespertina que aglutinó a jóvenes estudiantes y docentes del Departamento de Ciencias de la Educación de la FFyL (Brusilovsky, 2000). Precisamente en esta escuela se integrará Tedesco como parte del personal rentado estable.

El golpe de Estado en 1966 y la intervención de las universidades en julio de ese año tuvieron consecuencias graves para la UBA, en particular, para la FFyL, que vio desmantelado sus equipos y clausurado el DEU. La dictadura pretendía poner fin a la radicalidad política que se entremezclaba con la actividad académica. Entre el cuerpo docente, y también entre quienes participaban del proyecto extensionista en la Isla Maciel, se abrió un debate en torno a las modalidades de resistencia: buena parte decidió renunciar. Algunos de los cuales, como Gilda Romero Brest, encontrarán cobijo en el Instituto di Tella. Sus cargos en la FFyL serán ocupados por sectores provenientes del nacionalismo católico. Tedesco, en línea con la decisión asumida por su agrupación Política Obrera, optó por permanecer en la FFyL. Igualmente, se apresuró a rendir en calidad de libre las materias pendientes, graduándose hacia fines de 1968 como Licenciado en Cs. de la educación.

Al cerrarse el DEU, la nueva gestión en manos del interventor Luis Botet decidió trasladar al por entonces joven estudiante en calidad de trabajador no docente al Centro de Investigaciones Bibliotecológicas dependiente del rectorado de la UBA. Se le encomendó la tarea de catalogar fondos esparcidos en la Biblioteca del Centro de Estudiantes de Medicina, porque allí pasaría a funcionar el Centro de Estudios Superiores de Arte de la UBA que habían fundado Oscar Massota y César Janello. Aunque Massota no gravitó en la formación de Tedesco, le permitió acceder a fuentes documentales desconocidas. La directiva era clara: separar los libros ligados al arte; el resto de la bibliografía quedaba en libre disponibilidad. Allí se encontraban los informes periódicos del Consejo Nacional de Educación que incluían discursos de Ministros, datos estadísticos e informes de inspectores y directores de escuelas normales. Un copioso material que no pasará desapercibido por el aún entusiasta estudiante y constituirá la base empírica de su futuro libro.

En paralelo a este trabajo, y fruto del vínculo con Mari Griskan anidado en la Isla Maciel quien lo contactó con Daniel Rodríguez, Tedesco ingresó al Instituto Latinoamericano de Relaciones Internacionales (ILARI) en 1968. En Argentina, el Instituto contaba con la presencia de militantes de una tendencia contra la cual Tedesco había forjado su identidad política entrados los años 50: el liberal Partido Socialista Democrático (PSD). Entre otros, el propio Daniel Rodríguez que dirigía la revista Mundo Nuevo desde 1968 y fue decisivo en el ingreso de Tedesco al Instituto. 1968 también será especial para el flamante licenciado por el nacimiento de su hijo Sebastián hacia el mes de julio que, como en otras trayectorias de militantes, incidirá en su crisis con la política partidaria y el compromiso por aumentar las arcas familiares. Precisamente, el ILARI se volvía una atractiva opción: además de profesionalizar las actividades de investigación, prometía una inaudita holgura económica. Creado en Ginebra en el año 1966, el ILARI respondía al proyecto del Congress for Cultural Freedom que se fundó en Berlín a mediados de 1950 con sede 


\section{Los años de formación de Juan Carlos Tedesco. Su trayectoria política y académica durante las décadas del 50 y 60}

en París. En el marco de la segunda posguerra, el propósito central de esta institución era compensar, dentro de los conflictivos enfrentamientos políticoideológicos de la Guerra Fría, las intervenciones del bloque soviético. El Congreso incursionó en América Latina en 1953 a través de su revista órgano, Cuadernos (editada desde París entre 1953 y 1965), versión española de su homónima francesa. Entre el equipo encargado de propagar la revista en la región se encontraba un periodista anarquista belga exiliado después de la Guerra civil española: Louis Mercier Vega, quien residió en Chile durante la Segunda Guerra Mundial pero también en Argentina. En este sentido, ciertas expresiones locales del CLC se situaron a su izquierda: un firme anticomunismo pero desde posiciones tributarias del anarquismo, socialismo, liberalismo, y también troskismo. Como parte de las acciones del CLC, Vega asumió la orientación del ILARI en 1966 (Janello, 2012).

En nuestro país, jóvenes camadas se hicieron cargo de las sedes del ILARI. Tal fue el caso de Tedesco, al frente de la dirección de la sección de Ciencias Sociales del Instituto en Buenos Aires desde 1968 hasta su cierre en 1973. La confluencia del joven cientista de la educación con la institución es posible rastrearla en dos razones. Por un lado, la afinidad política con la opción anti stalinista desde posturas de izquierda. Una opción que, como se sugirió, había animado sus años de militancia. Por otro, en la promulgación por parte del Instituto de la emergente sociología científica entrados los años 60 (Janello, 2013). El ILARI diseminará tal enfoque en América Latina a través de su red revisteril: las más conocidas fueron Aportes (1966-1972, de perfil sociológico, editada en español, francés e inglés) y Mundo Nuevo (1966-1971, abocada a la cultura general), pero también existieron otras como la revista uruguaya Temas (1965-1968) o la propia Revista de Ciencias de la Educación (1970-1975), que dirigirá Tedesco.

Como se decía, el ILARI auspiciará las tareas de investigación de Tedesco que darán lugar al clásico libro Educación y Sociedad..., publicado por una pequeña editorial: Pannedille, en la colección Estudios Históricos y Sociales. La editorial era dirigida por quien había sido Profesor Titular del Departamento de Ciencias de la Educación (hasta la intervención en 1966) en Historia de la Educación Argentina e Historia de la Educación Universal de la FFyL: Gregorio Weinberg, quien además prólogo el mencionado libro. El prólogo, proveniente de una figura eminentemente reconocida en el ámbito cultural y educativo, resultó un apoyo decisivo para la rápida publicación y circulación de un libro destinado a intervenir en los debates educativos en curso, pero también a renovar radicalmente la manera de vincular educación y sociedad.

\section{A modo de cierre}

Se ha intentado abordar los años de formación de Juan Carlos Tedesco a través de jerarquizar sus incursiones políticas y académicas en los años 50 y 60. Al reponer 


\section{Sebastián Gómez}

características de los ámbitos políticos y académicos que modularon su temprana trayectoria, se buscó además advertir influencias sobre su clásico libro Educación y Sociedad.... Entre otras aristas, próximas exploraciones del itinerario del cientista de la educación en los 50 y 60 podrían precisar las características del barrio donde transcurrió buena parte de sus años infanto-juveniles, la trama política y teórica de la carrera de Ciencias de la Educación o los vínculos que el autor tejió con figuras gravitantes en su recorrido, tales como Juan Nervi o Gregorio Weinberg.

La indagación efectuada finaliza hacia 1969/70 cuando en el país, al calor también de luchas obreras y estudiantiles en otras latitudes, se abrirá un nuevo ciclo de protestas. Además de una renovada articulación de demandas sociales y políticas, en este ciclo gravitarán considerablemente vanguardias artísticas así como ensayos de renovación en áreas tales como la salud, la justicia y la ciencia. El ámbito educativo, que también participará en esta exploración, encontrará en Tedesco una figura emblemática. Tal gravitación se vuelve inteligible al reponer la trayectoria del maestro normal en espacios académicos y políticos en los 50 y 60 con una condición común: la presencia de jóvenes en una época en que eran llamados a modernizar y alterar la trama político-cultural. Tedesco será uno de estos jóvenes, dispuesto a impugnar el injusto orden y asumir el compromiso por un cambio social y educativo que seguramente imaginó inminente.

\section{Bibliografía}

Acha, 0. (2005). La trama profunda. Historia y vida en José Luis Romero. Bs. As.: Cielo por Asalto.

Adamovsky, E. (2009). Historia de la clase media argentina: apogeo y decadencia de una ilusión, 1919-2003. Bs. As.: Planeta.

Altamirano, C. (2001). Bajo el signo de las masas (1943-1973). Bs. As.: Ariel.

Amar, H. (2016). Bourdieu en el campo educativo argentino, 1971 - 1989. Bs. As.: Biblos.

Amaral, S. (2018). El movimiento nacional-popular. Gino Germani y el peronismo. Bs. As.: Universidad Nacional Tres de Febrero.

Bourricaud, F. (1980). Le Bricolage idéologique. Essai sur les intellectuels et les passions démocratiques. París: PUF.

Blanco, A. (2006). Razón y modernidad. Gino Germani y la sociología en la Argentina. Bs. As.: Siglo XXI.

Bourdieu, P. (1997). Razones Prácticas. Barcelona: Anagrama. 


\section{Los años de formación de Juan Carlos Tedesco. Su trayectoria política y académica durante las décadas del 50 y 60}

Bourdieu, P. (2011). Las estrategias de la reproducción social. Bs. As.: Siglo XXI.

Bourdieu, P. \& Passeron, L. (2003 [1964]). Los herederos. Bs. As.: Siglo XXI.

Buchbinder, P. (1997). Historia de la Facultad de Filosofía y Letras-UBA. Bs. As.: Eudeba.

Brusilovsky, S. (2000). Extensión universitaria y educación popular. Bs. As.: EUDEBA.

Cao, C., \& Gagliano, R. (2006). Habitando contornos poderosos: adolescencia, cultura y pedagogía social en los textos de Juan Mantovani. El pensamiento alternativo en la Argentina del siglo XX, 1939-1960.

Carlino, F. (1993). Transformaciones en la Carrera de Ciencias de la Educación de la UBA. Revista del IICE, (3), 80-90.

Cirigliano, G. (1967). Educación y futuro. Bs. As.: Paidós.

Cirigliano, G. (1969). (1969). Educación y política. Bs. As.: Librería del Colegio.

Dussel, I. (2018). Juan Carlos Tedesco y el pensamiento educativo: Reflexiones sobre un recorrido intelectual. Revista del IICE, (43), 39-52.

Elias, N. (1991). Mozart (Sociología de un genio). Barcelona: Península.

Germani, A. (2010). "Sobre la crisis contemporánea”. En Mera, C. y Rebón, J. (comp). Gino Germani. La sociedad en cuestión. Buenos Aires: Clacso.

Georgieff, G. (2008). Nación y revolución. Bs. As.: Prometeo.

Giussani, P. Partido y antipartido, La Vanguardia roja, 31-1-62.

Gramsci, A. (2003 [1949). Notas sobre Maquiavelo, sobre la política y sobre el Estado moderno. Bs. As: Nueva visión.

Herrera, C. M. (2016). ¿Adiós al proletariado? El Partido Socialista bajo el peronismo (1945-1955). Bs. As.: Imago Mundi.

Coggiola, 0. (2006). Historia del troskismo en Argentina y América Latina. Bs. As.: Razón y Revolución.

Janello, K. (2012). El Congreso por la Libertad de la Cultura de Europa a Latinoamérica: El caso chileno y la disputa por las "ideas fuerza” de la Guerra Fría, Izquierdas, 14, 14-52. 


\section{Sebastián Gómez}

Janello, K. (2013). El Boom latinoamericano y la Guerra Fría cultural. Nuevas aportaciones a la gestación de la revista "Mundo Nuevo", Ipotesi, 17, 115-133.

Kohn, L. (1999), Historia de Política Obrera, En Defensa del Marxismo, 24.

Manzano, V. (2018). La era de la juventud en Argentina. Bs. As.: FCE.

Murmis, M. (2010). Clases sociales en el primer Germani. En Mera, C. \& Rebón, J. (comp). Gino Germani. La sociedad en cuestión. Bs. As.: Clacso.

Neiburg, F. (1998). Los intelectuales y la invención del peronismo. Bs. As.: Alianza.

Neiburg, F. y Plotkin, M. (2004). Intelectuales y expertos. Bs. As.: Paidós.

O’Donnell, G. (1977). Estado y alianzas en la Argentina, 1956-1976, Desarrollo Económico, 16(64), 523-554.

Petra, A. (2017). Intelectuales y cultura comunista. Bs. As.: FCE.

Portantiero, J. C. (1973). Clases dominantes y crisis política en la Argentina actual, Pasado y Presente, 1, 31-64.

Pulfer, D. (2018). Juan Carlos Tedesco (1944-2017)-In Memoriam. Historia de la Educación. Anuario, 18(1).

Riccono, G. (2016). La Universidad de Buenos Aires de la Revolución Libertadora a la Noche de los bastones largos. Redes y trayectorias docentes. (Tesis doctoral). Universidad de Buenos Aires.

Rodríguez, L. G. (2013). Los católicos desarrollistas en Argentina. Educación y planeamiento en los años de 1960. Diálogos-Revista do Departamento de História e do Programa de Pós-Graduação em História, 17(1), 155-184.

Ruiz, G. (2015). Los aportes de Juan Carlos Tedesco al campo de la historia y la política de la educación argentina. En Arata, N. \& Ayuso, L. (eds). La formación de una comunidad intelectual. Bs. As.: Historia de la Educación Argentina.

Sarlo, B. (2001). La batalla de las ideas (1943-1973). Bs. As.: Ariel.

Sigal, S. (1991). Intelectuales y poder en la década del sesenta, Bs. As.: Ediciones Punto Sur.

Solari, M. (1949). Historia de la Educación argentina. Bs. As.: Paidós.

Suasnábar, C. (2004) Universidad e intelectuales. Educación y política en la Argentina (1955-1976). Bs. As.: FLACSO/Manantial. 
Los años de formación de Juan Carlos Tedesco. Su trayectoria política y académica durante las décadas del 50 y 60

Tarcus, H. (1996). El marxismo olvidado en la Argentina. Bs. As.: El Cielo por Asalto.

Tedesco, J. C. (1970). Educación y Sociedad en la Argentina (1880-1900). Bs. As.: Pannedille.

Tedesco, L. (2006). Lomas del Mirador. Bs. As.: Losada.

Terán, O. (1991). Nuestros años sesentas. Buenos Aires: Puntosur.

Tortti, M. (2009). El "viejo" Partido Socialista y los orígenes de la "nueva" izquierda". Bs. As.: Prometeo.

Tortti, M. (2014). Che, una revista de la nueva izquierda. Bs. As.: Cedinci.

Van Gelder, J. L., Cravino, M. C., \& Ostuni, F. (2013). Movilidad social espacial en los asentamientos informales de Buenos Aires. Revista Brasileira de Estudos Urbanos e Regionais, 15(2), 123-137.

Weber, M. (1944 [1922]. Economía y sociedad. Bs. As.: Fondo de Cultura Económica.

Recibido: $25 / 04 / 2020$

Evaluado: $21 / 05 / 2020$

Versión Final: 01/08/2020 